\title{
THE ROLE OF MOBILE INSTANT MESSENGER AS SUPPORTIVE PLATFORM FOR MEDICAL CAREER INTERVENTION
}

\author{
Rizma Adlia Syakurah ${ }^{1 *}$, Yayi Suryo Prabandari², Doni Widyandana ${ }^{2}$, Amitya Kumara ${ }^{3}$ \\ ${ }^{1}$ Departemen IImu Kesehatan Masyarakat, Fakultas Kesehatan Masyarakat, Universitas Sriwijaya \\ ${ }^{2}$ Fakultas Kedokteran, Kesehatan Masyarakat dan Keperawatan, Universitas Gadjah Mada, Yogyakarta - INDONESIA \\ ${ }^{3}$ Fakultas Psikologi, Universitas Gadjah Mada, Yogyakarta - INDONESIA
}

Submitted: 16 Nov 2018; Final Revision from Author: 13 Nov 2020; Accepted: 06 Jan 2021

\begin{abstract}
Background: Career intervention in medical students is an activity meant to increase awareness and early exposure on various medical careers. Utilization of technology as a support to career intervention model offers a novel approach that might optimize the exposure and quality of the intervention and can be developed as a safe and non-judgemental environment for the students to talk about career-related topics.
\end{abstract}

Aims: Thisstudy aimed to determine the use ofmobile instantmessenger as a supportivetoolformedical careerintervention.

Learning Media Review: LineTM is a mobile instant messenger platform that is used to communicate and send messages using the internet. This platform provides voice and video calls, text messages, polls, and other features such as: stickers, photos, videos, voice messages, and location. These features can be accessed free of charge by users. This article uses discussion and participatory observation methods for three weeks. Thirty six $(n=36)$ first-year medical students that were joining a career introduction course were placed into on online group, a LineTM group, led by two facilitators to guide their daily discussion. The responses are voluntary and they were encouraged to express themselves freely without any topic restriction whatsoever throughout the sessions. Online transcripts were then coded according to recurring topics and themes that came up during their discussions. Eight themes were identified from the discussion and categorised into three: 3 major categories, 2 intermediate and 3 minor. Major themes identified were role model, non-academic career information, and clinical clerkship. This study show maximum engagement of 26 participants on first day with maximum discussion length in one topic of three hours during career-related topics.

Conclusion: Mobile instant messaging is considered useful in supporting a medical career intervention, especially in providing career information and carrying a momentum for career-related discussion. It is further stated that the role of online facilitator as a peer mentor is major in providing quality discussion, a safe environment, and accurate source of information to the students.

Keywords: career choice, medical career, undergraduate, instant messenger

\begin{abstract}
ABSTRAK
Latar belakang: Intervensi karir mahasiswa kedokteran merupakan kegiatan yang dilakukan dengan tujuan memberikan pengenalan dan pemaparan variasi karir secara dini bagi mahasiswa. Penggunaan teknologi sebagai alat pendukung intervensi karir mulai digunakan dalam mendukung tercapainya keterpaparan yang optimal dan ruang bagi mahasiswa untuk berdiskusi mengenai pilihan karir merek.
\end{abstract}

*corresponding author, contact: rizma.syakurah@gmail.com 
Tujuan: Penelitian ini bertujuan untuk menggali peran mobile instant messenger sebagai moda pendukung intervensi karir kedokteran.

Review media pembelajaran: Line ${ }^{T M}$ adalah salah satu platform mobile instant messenger yang digunakan untuk berkomunikasi dan berkirim pesan dengan menggunakan internet. Platform ini menyediakan fitur panggilan suara danvideo, pesanteks, polling, danfitur lainnya seperti:stiker, foto, video, pesan suara, dan lokasi. Fitur-fitur tersebut dapat diakses secara gratis oleh pengguna. Artikel ini menggunakan metode diskusi dan observasi dalam grup mobile instant messenger selama jangka waktu tiga minggu. Tiga puluh enam ( $\mathrm{n}$ = 36) mahasiswa kedokteran tahun pertama yang sedang mengikuti kegiatan pengenalan karir kedokteran digabungkan dalam satu grup $\operatorname{Line}^{T M}$ yang dipimpin oleh dua fasilitator online untuk memandu diskusi harian mereka. Tanggapan dari mahasiswa bersifat sukarela dan bebas, dan tidak dilakukan pembatasan dalam topik-topik yang dibahas. Transkrip online yang telah didapatkan kemudian diberi kode sesuai dengan topik dan tema berulang yang muncul selama diskusi mereka. Delapan tema yang berhasil diidentifikasi dari diskus dikelompokkan pada tiga kategori yaitu 3 kategori mayor, 2 intermediet, dan 3 minor. Tema mayor yang muncul adalah role model, informasi karir non-akademik, dan kepaniteraan klinik. Penelitian ini menunjukkan keterlibatan diskusi secara maksimal terjadi pada hari pertama dengan jumlah 26 peserta dengan lama diskusi secara maksimal dalam satu topik yaitu tiga jam pada topik mengenai pilihan karir.

Kesimpulan: Penggunaan platform online, yaitu mobile instant messenger, dapat digunakan sebagai platform pendukung dalam intervensi karir kedokteran, terutama dalam pemberian informasi dan sebagai wahana diskusi mengenai topik terkait karir bagi mahasiswa kedokteran. Selain itu, peran fasilitator sebagai peer mentor berperan penting dalam meningkatkan kualitas, kepercayaan, dankeakuratan informasiselama diskusi.

Kata kunci: pilihan karier, karir kedokteran, mahasiswa, pesan instan

\section{PRACTICE POINTS}

- Tersedia secara online dan dapat diunduh dengan gratis sebagai metode diskusi.

- Mendukung diskusi berbiaya rendah berbagaitingkatan mahasiswa dan narasumber.

\section{PENDAHULUAN}

Keputusan pemilihan karir setelah menyelesaikan jenjang pendidikan profesi kedokteran merupakan salah satu keputusan yang paling penting untuk dilakukan oleh seorang mahasiswa kedokteran. ${ }^{1}$ Pilihan karier di bidang kedokteran dipengaruhi oleh berbagai macam faktor yang diperoleh dari preferensi siswa sebelum memasuki sekolah kedokteran, rekomendasi dan saran keluarga, serta adanya paparan selama perkuliahan..$^{2-3}$ Dalam melakukan perencanaan daneksplorasikariryang sesuai dengan minat dan bakatnya, mahasiswa terkadang mencari dukungandan bantuan dariorang lain yang memiliki informasi atau memiliki hubungan dengan jalur karir tertentu melalui konseling, konsultasi pribadi, dan eksplorasi karir. ${ }^{4}$

Layanan konseling online yang kini tersedia dalam berbagai format dan diprediksikan jumlahnya akan terus meningkat dalam 10 tahun ke depan sesuai dengan perkembangan jaman dan perannya dalam membantu eksplorasi karir. ${ }^{5}$ Penelitian yang berfokus pada penerapan konseling online saat ini terus berkembang, seperti konseling pilihan karier, konseling psikologis pribadi yang berhubunganan dengan kekhawatiran dan tekanan dalam perkuliahan sehari-hari, serta konseling online yang berfokus pada kesehatan bagi mahasiswa. ${ }^{6-8}$ Penelitian sebelumnya juga menunjukkan bahwa intervensi konseling yang 
disampaikan secara online cenderung membantu untuk memberikan jangkauan yang lebih luas dalam kegiatan perkuliahan. ${ }^{8-12}$ Mobile instant messenger sebagai media online seringkali digunakan dalam proses pendidikan, khususnya sebagai media dokumentasi, diskusi, konstruksi dengan umpan balik sesama rekan kuliah, bantuan dalam kegiatan perkuliahan, dan juga sebagai media penilaian dalam proses perkuliahan.

Pemanfaatan platform online dapat meningkatkan kualitas dan efektifitas suatu intervensi karir, sehingga penelitian ini dilakukan untuk menggali peran mobileinstantmessengersebagai alat pendukung dalam suatu internvensi karir kedokteran.

\section{REVIEW MEDIA PEMBELAJARAN}

Line $^{\mathrm{TM}}$ adalah salahsatu platformmobile instant messenger yang digunakan untuk berkomunikasi dan berkirim pesan dengan menggunakan internet. Line ${ }^{\mathrm{TM}}$ dapat diunduh secara gratis melalui playstore (android) dan Appstore (iOS). Platform ini menyediakan fitur panggilan suara dan video, pesan teks, polling, dan fitur lainnya seperti: stiker, foto, video, pesan suara, dan lokasi. Fitur-fitur tersebut dapat diakses secara gratis oleh pengguna. Penelitian ini menggunakan model observasi partisipatif pada diskusi mahasiswa dalam grup mobile instant messenger yang berlangsung selama selama tiga minggu. Peserta direkrutsecara sukarela dari mahasiswa kedokteran tahun pertama di Universitas Sriwijaya. Tiga puluh enam $(n=36)$ mahasiswa kedokteran bergabung dengan kegiatan pelatihan pengenalan karier (MedJob ${ }^{\text {TM}}$ ) dan secara bersamaan dimasukkan ke dalam satu kelompok Mobile Internet Messenger (MIM) yang dipimpin oleh dua orang fasilitator. Platform MIM yang dipilih adalah Line ${ }^{\mathrm{TM}}$. Selama tiga minggu tersebut fasilitator memandu diskusi mereka dan memberi mereka stimulasi untuk merefleksikan diri tentang pilihan karier serta masalah pribadi yang mereka temui selama perkuliahan yang menyebabkan hambatan dalam eksplorasi karir mereka menggunakan jadwal dan materi yang telah disiapkan sebelumnya. Transkrip onLine diberi kode sesuai dengan topik dan tema berulang yang muncul selama diskusi mereka. Penelitian dimulai pada November 2016. Fasilitator dipilih dari mahasiswa kedokteran tahun kelima yang berada dalam kepaniteraan klinik dan aktif dalam organisasi dengan Indeks Prestasi Kumulatif (IPK) yang tinggi berkisar 3,50-4,00 (Cumlaude). Mereka diberi pengarahan tentang topik kedokteran sehari-hari, materi pengenalan karir yang disertakan dengan gambar, video, dan pedoman dasar untuk diskusi. Panduan diskusi dibuat dengan gambar dan pertanyaan untuk memancing diskusi. Jadwal diskusi minimal dijadwalkan sesuai dengan bagan di bawah ini, tentunya dengan setting yang lebih longgar dan disesuaikan dengan keinginan peserta.

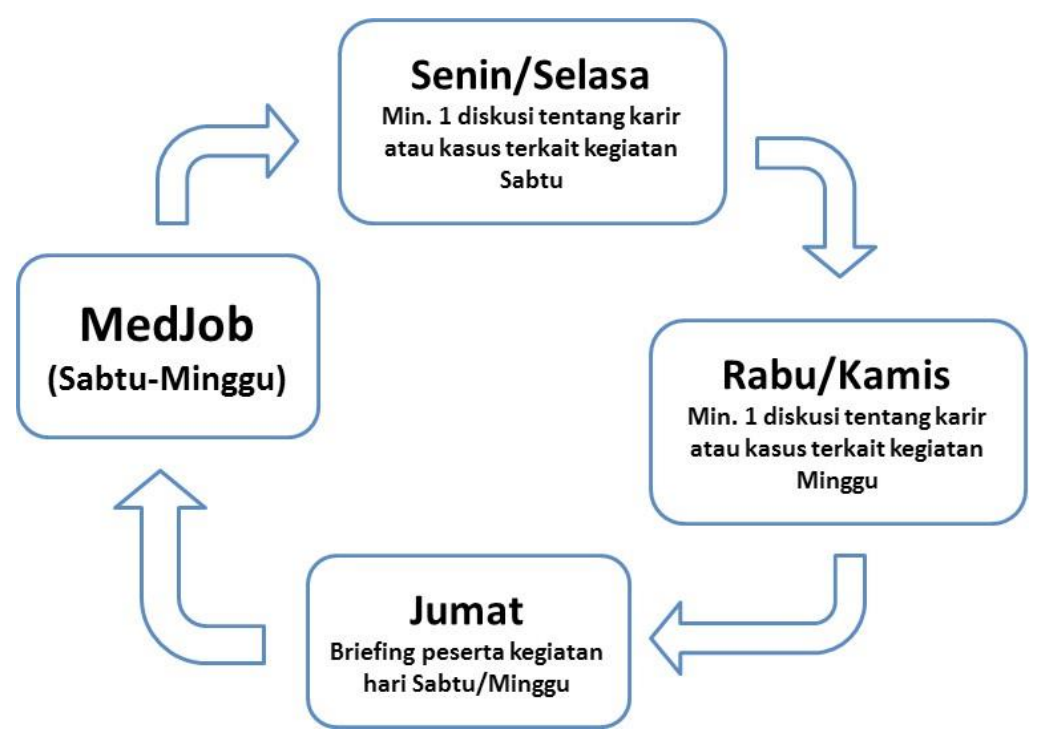

Gambar 1. Panduan minimal kegiatan Line ${ }^{\mathrm{TM}}$ 
Dalam analisis data, penulis dan seorang asisten meninjau transkrip Line $^{\mathrm{TM}}$ secara independen selamatiga kali dan mengkodekannya sesuai dengan topik dan tema yang berasal dari diskusi. Transkrip kemudikan dikodekan secara manual dengan tangan dan dilanjutkan dengan pembuatan spreadsheet untuk mempermudah kategorisasi. Studi ini telah mendapatkan persetujuan dari Komite Etika Fakultas Kedokteran Universitas Sriwijaya.

\section{Evaluasi Media Ajar}

Hasil analisis konten diskusi grup online menunjukkan adanya 8 tema yang berkaitan dengan penentuan pilihan karier kedokteran:3tema mayor, 2 intermediet, dan 3 tema minor (Tabel 1). Tema mayor, sebagai tema utama yang mendominasi di semua sesi chat, yaitu role model, informasi karir nonakademik, dan kepaniteraan klinis. Tema intermediet yang muncul dalam lebih dari setengah chat adalah konfirmasi tentang karir kedokteran dan tips terkait persiapan dan adaptasi di fakultas kedokteran. Tema minor yang muncul selama diskusi adalah konsultasi personal dengan fasilitator, fasilitas di rumah sakit, dan variasi penyakit serta penatalaksanaannya. Tema major dijelaskan secara spesifik di sub-bab berikut.

Tabel 1. Tema yang diidentifikasi dari obrolan grup di LineTM Group

\begin{tabular}{ll}
\hline Mayor & Role model \\
& Kehidupan pribadi \\
& Kesempatan karir \\
& Tips dan trik \\
& Informasi karir non-akademik \\
& Senioritas dalam residensi \\
& Aktivitas sehari-hari \\
& Biaya tambahan selama residensi \\
& Kepaniteraan klinis \\
& Pengalaman pribadi \\
& Persiapan \\
& Konfirmasi terkait karir kedokteran \\
& Tips dalam mengatur dan menyiapkan kuliah kedokteran \\
Intermediet & Konsultasi personal \\
Minor & Fasilitas rumah sakit \\
& Penyakit dan talaksana
\end{tabular}

Diskusi dalam grup online tersebut membahas terutama mengenai pertanyaan-pertanyaan pribadi dan sensitif tentang role model, informasi yang tidak resmi dan non-akademik tentang karier tertentu, dan pengalaman pribadi dari para fasilitator. Menggunakan platform online untuk menanyakan pertanyaan pribadi dan sensitif sesuai dan efektif, dimana konseling online cenderung membantu untuk memberikan jangkauan yang lebih besar di kampus selama proses perkuliahan. ${ }^{8-12}$

Keterlibatan peserta maksimum selama diskusi adalah sebanyak 26 orang pada hari pertama, dan lama diskusi maksimum dalam satu topik adalah tiga jam selama topik yang terkait dengan karier kedokteran.

\section{Role model}

Role model dan kehidupan pribadi mereka sehari-hari tampaknya dianggap sebagai topik yang menarik dalam perspektif peserta. Mereka menanyakan berbagai pertanyaan mengenai kehidupan sehari-hari role model, kisah sukses mereka, peluang karier, dan panduan tentang bagaimana mencapai kesuksesan yang sama. Beberapa peserta langsung mem-'follow' dan memberikan 'like' pada akun sosial media sosial 
role model dan berdiskusi dengan kelompok tentang kegiatan kedokteran yang diposting role model dalam akun sosial media mereka dan membuat peserta menjadi lebih terinspirasi. Pertanyaan yang diajukan lebih bersifat pribadi dan sensitif yang jarang ditanyakan pada seminar, lokakarya atau kegiatan formal lainnya berkaitan dengan konsultasi karier kedokteran. Diskusi melalui online messenger memberi para peserta lebih banyak keberanian untuk bertanya tentang hal-hal semacamitu.

"Saya lihat akun Facebook dr. X kemarin dan saya lihat postingan beliau tentang operasi jantung, itu keren banget!" (LG 2-8)

\section{Informasi karier non-akademik}

Para peserta mengajukan pertanyaan dan mengkonfirmasi informasi yang mereka dengar sebelumnya, beberapa pertanyaan tersebut mungkin sulit jika ditanyakan langsung pada kenalan yang terakit. Masalahtentang senioritas dan berapabanyak uang yang harus mereka siapkan di luar biaya kuliah resmi yang juga tidak mudah ditanyakan, namun peserta meminta klarifikasi informasi tersebut dalam grup diskusi. Beberapa informasi, prasangka, dan desas-desus berasal dari lingkungan peserta, drama di televisi, dan dari berita.

"Kak, bisa gak jelasin tentang senioritas seputar kehidupan dokter dan residen?"

"Hal kayak gitu pantang ditanyain ya kak?”(LG01-11)

Pertanyaan yang sensitif dan non-akademik yang tidak dapat dijawab melalui Google atau situs web universitas, dan situasi yang berbeda dari universitas ke universitas, serta dari waktu ke waktu. Keberadaan grup Line ${ }^{T M}$ sangat membantu untuk mengklarifikasi desas-desus yang tidak memiliki dasar, menambah informasi tentang peraturan atau sistem terbaru, dan membantu mahasiswa mempersiapkan diri untuk menghadapi situasi nyata di kemudian hari.

\section{Kepaniteraan klinik}

Memilih mahasiswa kedokteran tahun terakhir sebagai fasilitator dan peer-mentor memberikan kemudahan tertentu dalam memberikan informasi dan tips tentang apa yang harus disiapkan dalam waktu dekat. Para peserta sangat tertarik untuk mengajukan berbagai pertanyaan mengenai persiapan yang diperlukan untuk memasuki kepaniteraan klinik dan lulus dengan lancar, juga menanyakan tentang pengalaman pribadi fasilitator selama rotasi mereka dalam kepaniteraan klinik. Kepaniteraan klinik adalah langkah pertama dalam proses perkuliahan yang nyata bagi mahasiswa kedokteran dan merupakan salah satu proses eksplorasi karier yang utama untuk memantapkan tujuan mereka di masa depan.

Berdasarkan penelitian ini, keterlibatan diskusi secara maksimal menggunakan grup Line ${ }^{\mathrm{TM}}$ adalah 26 peserta pada hari pertama dengan panjang diskusi maksimal dalam satu topik adalah tiga jam selama Mombassa topik yang berhubungan dengan karier kedokteran. Mahasiswa kepaniteraan klinik adalah fasilitator yang baik untuk kelompok tersebut. Mereka berfungsi sebagai jembatan antara siswa dan role model, peer-mentor, dan panutan bagi dirinya sendiri. Kesenjangan usia yang kecil membuat para mahasiswa merasa nyaman bertanya tentang pertanyaan-pertanyaan yang sensitif sekalipun. Mahasiswa menyatakan bahwa mereka menikmati diskusi melalui grup Line ${ }^{\mathrm{TM}}$ dan beberapa dari mereka menganggapnya sebagai salah satu kegiatan favorit mereka dalam MedJob. Grup Line ${ }^{\mathrm{TM}}$ menurunkan risiko drop-out selama kursus perkenalan karier, karena fasilitator terus memberikan topik yang terkait dengan mahasiswa untuk dibicarakan sehingga mendorong mereka untuk terus menghadiri kursus.

\section{KESIMPULAN}

Mobile instant messenger dapat digunakan sebagai platform pendukung untuk memberikan informasi seputar pilihan karier mahasiswa kedokteran. Peran fasilitator juga sangat penting sebagai peermentor untuk merangsang diskusi dan memberikan informasi yang valid dan dapat diandalkan tentang pilihan karier mahasiswa kedokteran.

\section{SARAN}

Penelitian ini dapat dijadikan landasan sebagai moda pendukung intervensi karir kedokteran. Peneliti selanjutnya diharapkan dapat mengeksplor aplikasi mobile instant messenger lainnya dan menganalisis 
perbandingan efektitivitas platform pendukung intervensi karir kedokteran.

\section{UCAPAN TERIMA KASIH}

Penulis mengucapkan terimakasih kepada semua partisipan atas waktu dan kontribusi yang telah diberikan untuk penelitian ini.

\section{DEKLARASI KEPENTINGAN}

Para penulis mendeklarasikan bahwa tidak terdapat konflik kepentingan apapun terkait studi pada naskah ini.

\section{KONTRIBUSI PENULIS}

Rizma Adlia Syakurah - menyusun kerangka konsep, merencanakan penelitian, melaksanakan pengambilan dan analisis data, menulis draft manuskrip, menyetujui versi terakhir dari makalah penelitian.

Yayi Suryo Prabandari - penyusunan kerangka konsep dan mengedit makalah penelitian, dan menyetujui versi terakhir dari makalah penelitian.

Doni Widyandana - penyusunan kerangka konsep dan mengedit makalah penelitian, dan menyetujui versi terakhir dari makalah penelitian.

Amitya Kumara - penyusunan kerangka konsep dan mengedit makalah penelitian, dan menyetujui versi terakhir dari makalah penelitian.

\section{DAFTAR PUSTAKA}

1. AKwok J, Wu V, Sanfilippo A, Bowes K, Pinchin $S$. Examining the impact of early longitudinal patient exposure on medical students' career choices. Canadian Medical Education Journal. 2017; 8(1).

2. Korkmaz, $\mathrm{H}$. The Characteristics of Medical Students and Motivation Towards Career Choice: Implications for Curriculum. H. U. Journal of Education. 2013;28(1):258-268.

3. Syakurah RA, Prabandari YS, Widyandana, Kumara A. Career choices, determinants, and need for medical career introduction among medical students. Int J Res Med Sci. 2017; 5: 1998-2002.

4. Rogers ME, Creed PA, Glendon AI. The role of personality in adolescent career planning and exploration: A social cognitive perspective. Journal of Vocational Behavior. 2008; 73: 132142.

5. Mallen MJ, Vogel DL, Rochlen AB, Day S. Online Counseling: Reviewing the Literature From a Counseling Psychology Framework. The Counseling Psychologist. 2005; 33(6): 819-871.

6. Haberstroh S, Parr G, Bradley L, MorganFleming B, Gee R. Facilitating online counseling: Perspectives from counselors in training. Journal of Counseling \& Development. 2008; 86: 460470.

7. Maples M, Han S. Cybercounseling in the United States and South Korea: Implications for counseling college students of the millennial generation and the networked generation. Journal of Counseling \& Development. 2008; 86: 178-183.

8. Di Fabio A. Life design and career counseling innovative outcomes. The Career Development Quarterly. 2016 Mar 1; 64(1): 35-48.

9. Lange A, Van De Ven JP, Schrieken B. Interapy. Treatment of posttraumatic stress through the Internet: A controlled trial. Journal of Behavior Therapy and Experimental Psychiatry. 2003; 32: 73-90.

10. Rassau A, Arco L. Effects of chat-based online cognitive behavior therapy on study related behavior and anxiety. Behavioural and Cognitive Psychotherapy. 2003; 31:377-381.

11. Richards J, Klein B, Carlbring, P. Internet-based treatment for panic disorder. Cognitive Behavior Therapy. 2003; 32: 125-135.

12. Haas A, Koestner B, Rosenberg J, Moore D, Garlow S, Sedway J. et al. An interactive Webbased method of outreach to college students at risk for suicide. Journal of American College Health. 2008; 57: 15-22. 